\title{
A qualitative study of perceived barriers to hepatitis C care among people who did not attend appointments in the non-urban US South
}

Jacqueline E. Sherbuk ${ }^{1 *}$ D, Alexa Tabackman², Kathleen A. McManus ${ }^{1}$, Terry Kemp Knick', Julie Schexnayder ${ }^{1}$, Tabor E. Flickinger ${ }^{3}$ and Rebecca Dillingham

\begin{abstract}
Background: Most people diagnosed with hepatitis C virus (HCV) have not linked to care, despite the availability of safe and effective treatment. We aimed to understand why people diagnosed with HCV have not pursued care in the non-urban Southern United States.

Methods: We conducted a survey and semi-structured interview with participants referred to an HCV clinic who did not attend an appointment between 2014 and 2018. Our clinic is located in a non-urban region of Virginia at a university hospital. Qualitative data collection was guided by the Health Belief Model (HBM). Data was analyzed using qualitative content analysis to identify key factors influencing patient perceptions regarding HCV and pursuit of care.

Results: Over half of previously referred patients $(N=200)$ could not be reached by phone. Eleven participants enrolled, including 7 men and 4 women. Based on survey responses, unreliable transportation, unstable housing, substance use, and lack of insurance were common. Participants demonstrated good knowledge of HCV disease, complications, and treatment. On qualitative analysis of semi-structured interviews, final themes emerged from within and between HBM constructs. Emerging themes influencing patient perceptions included (1) structural barriers, (2) stigma, (3) prior experiences of HCV disease and treatment, (4) discordance between the recognized severity of HCV and expected impacts on one's own health, and (5) patient-provider relationship. Substance use was not identified to be a barrier to care.

Conclusions: Participants perceived individual and structural barriers to linking to care. A strong HCV knowledge base was not sufficient to motivate pursuit of care. Efforts to improve linkage to care must address barriers at multiple levels, and system-level changes are needed. As the majority of previously referred patients could not be contacted by phone, current approaches to patient engagement are not effective for reaching these populations. Expansion of HCV care to primary care settings with an established patient-provider relationship or co-located treatment within substance use treatment programs may serve to increase access to HCV treatment.
\end{abstract}

Keywords: Hepatitis C, Linkage to care, Content analysis, Substance use, Stigma, Health Belief Model

\footnotetext{
* Correspondence: jes2nk@virginia.edu

'Division of Infectious Diseases and International Health, Department of Medicine, University of Virginia, Charlottesville, VA, USA

Full list of author information is available at the end of the article
}

(c) The Author(s). 2020 Open Access This article is licensed under a Creative Commons Attribution 4.0 International License, which permits use, sharing, adaptation, distribution and reproduction in any medium or format, as long as you give appropriate credit to the original author(s) and the source, provide a link to the Creative Commons licence, and indicate if changes were made. The images or other third party material in this article are included in the article's Creative Commons licence, unless indicated otherwise in a credit line to the material. If material is not included in the article's Creative Commons licence and your intended use is not permitted by statutory regulation or exceeds the permitted use, you will need to obtain permission directly from the copyright holder. To view a copy of this licence, visit http://creativecommons.org/licenses/by/4.0/. The Creative Commons Public Domain Dedication waiver (http://creativecommons.org/publicdomain/zero/1.0/) applies to the data made available in this article, unless otherwise stated in a credit line to the data. 


\section{Introduction}

The USA and the World Health Organization have established goals for elimination of hepatitis $\mathrm{C}$ virus (HCV) by $2030[1,2]$. Cure of HCV improves patientrelated outcomes, reduces complications related to cirrhosis and liver cancer, and prevents ongoing virus transmission [3, 4]. The HCV care cascade identifies the essential steps of $\mathrm{HCV}$ care necessary to achieve cure. The cascade begins with all people infected with $\mathrm{HCV}$, and steps include diagnosis of affected individuals, linkage to specialty care, treatment, cure, and monitoring for reinfection [5]. The linkage to care (LTC) step requires that patients who are diagnosed are connected to a program or provider offering $\mathrm{HCV}$ care. In the USA, treatment has historically required specialist care, and patients must be linked from the public health or screening program where they were diagnosed to a specialty provider offering $\mathrm{HCV}$ treatment. National studies estimate that only $17 \%$ of people diagnosed with $\mathrm{HCV}$ have been linked to specialty care [6], and the current model of care is unlikely to result in $\mathrm{HCV}$ elimination [3]. Additionally, LTC rates may be plateauing, or even declining, following treatment of an initial group of highly motivated patients who sought care once DAAs were available $[6,7]$.

The rural US South has been disproportionately affected by HCV, in part due to the opioid crisis $[8,9]$. $\mathrm{HCV}$ is highly prevalent in people who inject drugs and incarcerated populations $[10,11]$. People living in the rural Appalachian region of the USA face a risk environment that may further contribute to the high burden of $\mathrm{HCV}$ through intergenerational poverty, geographic isolation, as well as limited employment and enrichment opportunities [12]. Poverty, homelessness, and unemployment also pose structural barriers for engagement in healthcare [13]. Among these marginalized populations, the presence of effective treatment alone is not sufficient to increase engagement with $\mathrm{HCV}$ care $[14,15]$. This risk environment contributes to the high burden of HCV.

Varied models of care have been implemented to improve LTC, including nurse-driven care, case management, and peer support [16]. In our HCV referral clinic in the non-urban Southern United States, implementation of a nurse navigator model led to a $76 \%$ LTC rate [17]. Yet even in this high-intensity outreach model of patient education and care coordination, nearly a quarter of patients did not see a specialty provider at least 6 months following referral. The nurse navigator maintained a database including reason for not linking to care, as perceived by the nurse navigator, and the most common reasons provided included multiple no-shows to scheduled appointments, inability to contact patients to schedule an initial visit, and incarceration [17]. The reasons for missed appointments for $\mathrm{HCV}$ care are often complicated and diverse [18], incorporating patientrelated, provider-related, and health system-related barriers [19].

Patient perceptions regarding HCV care may be changing with the availability of direct acting antivirals (DAAs), which have simplified and improved the tolerability and effectiveness of $\mathrm{HCV}$ treatment. The purpose of this study was to better understand why people diagnosed with HCV in the non-urban Southern United States have not pursued specialty HCV care in this era of safe and effective treatment.

To achieve our aim of understanding patient perceptions of HCV and influence of these perceptions on pursuit of HCV care, we utilized the Health Belief Model (HBM) as a guiding framework. The HBM was developed to explain engagement in health-promoting behavior as a function of six central constructs: perceived susceptibility, perceived severity, perceived benefits, perceived barriers, cues to action, and self-efficacy [20-22]. The HBM has been used to explore patient adoption of recommended care practices for asymptomatic conditions where patient beliefs may be most important in making medical decisions [23]. Given the chronic and often asymptomatic nature of $\mathrm{HCV}$, this model was appropriate for our objective. Certain constructs, including perceived barriers and cues to action, allow consideration of external factors. As barriers to HCV care occur at multiple levels, inclusion of external factors is essential.

\section{Methods}

\section{Clinical setting}

This study took place at the University of Virginia (UVA) Infectious Diseases HCV clinic [17]. UVA is a non-urban, tertiary care, safety net hospital serving the western portion of the state of Virginia including the rural Appalachian region. Safety net hospitals care for patients regardless of ability to pay or health insurance status [24]. Referral sources include internal referrals from within the UVA health system, external referrals from community-based providers and health departments, and self-referrals. The HCV clinic staff includes physicians, a full-time nurse coordinator, and a pharmacy team. The nurse coordinator will make multiple attempts to reach referred patients through phone or mail, reschedule missed appointments, assist patients with required paperwork, complete prior authorizations, and provide general education regarding $\mathrm{HCV}$ over the phone. Two visits are required to receive treatment: (1) a provider visit and (2) imaging for staging of liver disease. Health insurance is not required. Through insurance coverage, with co-pay assistance if needed, and patient assistance programs, the nurse coordinator has 
been able to obtain medications for all eligible patients during the study time period [17].

\section{Study design and study population}

The study population was defined to be all patients ages 18 years and older, who were referred for HCV care between November 2014 and March 2018, but who did not attend an HCV clinic visit by June 2018. This study was approved by the UVA Health Sciences Research Institutional Review Board and participants provided verbal informed consent.

The UVA Infectious Disease HCV clinic received 834 referrals for $\mathrm{HCV}$ treatment during this period. All patients who met the inclusion criteria $(n=200)$ were eligible for study recruitment. Interviews took place during June to August 2018 and were performed over the phone by two study personnel. Telephone recruitment was determined to be the least intrusive and only practical way to recruit participants from a cohort who did not attend their clinic appointment. Recruitment through telephone minimized barriers to participation, and telephone interviews have been demonstrated to provide rich qualitative data $[25,26]$. We considered recruitment through mail or in-person, and both were deemed inappropriate. The 200 eligible patients were placed in a random order list. Consecutive sampling was used with attempts to contact all eligible patients by telephone using the random order list. The participants did not have a prior relationship with the interviewers. Research goals and the role of the interviewers in the study were explained to the participants. Participants were asked if they were in a comfortable setting where they could talk freely on the phone. Participants were given an opportunity to ask questions and to request participation at a later date, if preferred. Participation in the study required approximately $30-60 \mathrm{~min}$, and participants received compensation for their time.

\section{Data collection}

A survey and semi-structured interview were administered verbally. The survey was designed to evaluate demographic characteristics, experiences with the medical system, trust in the medical system [27], selfevaluation of overall health [28], HCV knowledge, and previously documented barriers to $\mathrm{HCV}$ care including unstable housing [29,30], unreliable transportation, and history of drug and alcohol use [31, 32]. Survey questions were based on validated measurements when available, including questions regarding housing stability, self-evaluation of health, and drug and alcohol use. Knowledge questions were adapted from the literature and public health resources [2, 33, 34].

The semi-structured interview guide included questions related to each of the HBM constructs.
Interviewers proceeded through the constructs in the same order for each participant and were instructed to ask clarifying questions or pursue new ideas raised by participants as indicated. Interviews were audiorecorded and transcribed verbatim. Questions explored patients':

- Perceived susceptibility to complications of HCV by asking about how they feel about the impact of HCV on their health now and in the future;

- Perceived severity of HCV by asking about whether $\mathrm{HCV}$ was perceived to be a serious medical disease and any friend or family experiences with $\mathrm{HCV}$ complications and treatment;

- Perceived benefits of pursuing HCV care by asking participants about whether they felt seeking care and treatment would be effective and beneficial to their health;

- Perceived barriers by asking participants about what has gotten in the way of pursuing care;

- Self-efficacy by asking participants about how confident they are in their ability to pursue $\mathrm{HCV}$ care and treatment if they choose to do so;

- Cues to action by asking participants about what would make them more likely to pursue treatment in the future.

\section{Data analysis}

Frequency analysis was used for survey data. Interviews were imported into Dedoose for analysis (Dedoose Version 8.0.35, web application for managing, analyzing, and presenting qualitative and mixed method research data (2018). Los Angeles, CA: SocioCultural Research Consultants, LLC www.dedoose. com). Conventional content analysis was used to identify the key factors influencing patient perceptions regarding $\mathrm{HCV}$ and decisions regarding pursuing care [35]. An initial codebook was developed inductively and modified as additional themes emerged from the interviews. Codes and descriptions that were applied inconsistently by study team members were revised. Each interview was coded by at least two members of the research team. Richness and quality of the data were assessed concurrently with data analysis throughout the iterative development of the themes. Thematic saturation was achieved after analysis of the first eight interviews with no additional codes required after that point. After all eleven interviews had been coded, the team grouped the codes by consensus according to the HBM constructs. If codes did not fit into a construct, a new group was created. Final themes emerged from within and between HBM categories. 


\section{Results}

\section{Study participants}

Of the 200 patients meeting inclusion criteria, 184 had contact information available. Of these, 99 could not be reached by telephone despite up to three attempts, 64 declined participation, and 8 initially expressed interest in participation but could not find a potential time to talk with interviewers. Specific reasons for declining to participate were not elicited from those approached. Thirteen people provided consent to participate. Of these, 12 individuals completed the survey and 11 individuals completed both the survey and the interview.

Of the 11 participants who completed the entire study, the mean age was 48.2 (standard deviation 13.6) years with a range of 24 to 64 years, 7 (64\%) were men, and 9 $(82 \%)$ were white (Table 1$)$. Nearly all had seen a physician in the past year, but only 6 (55\%) had an established primary care provider. Over one-third were uninsured. Unstable housing and transportation were common, present for $4(36 \%)$ and $5(45 \%)$ of participants respectively. Five (45\%) reported using drugs in the past year with 3 (27\%) reporting drug use in the past month. All participants were aware of their diagnosis of $\mathrm{HCV}$ and that they had been referred for specialty care. Trust in medical systems was highly variable among participants. The majority of participants were referred to the HCV clinic in 2017.

For each of six HCV knowledge questions, at least 9 of the 11 participants answered correctly (Table 2). Each participant correctly answered over half of the questions, with 4 (36\%) correctly answering four questions, 3 (27\%) correctly answering five questions, and 4 (36\%) correctly answering all six questions.

\section{Qualitative analysis}

The complete codebook with code descriptions, example quotes, and frequencies is presented in the Supplementary Table. While interviews were structured using the HBM, the most impactful themes arose in multiple constructs. For this reason, emerging cross-construct themes are presented here (Table 3). The key emerging themes included structural barriers to care, stigma, prior experiences with HCV through self or others, ambivalence, and patient-provider relationships.

\section{Structural barriers}

Nearly all participants perceived treatment to be beneficial, yet multiple barriers prevented participants from pursuing $\mathrm{HCV}$ care. Common structural barriers included financial costs of treatment, unclear (or complex) referral and treatment processes, limited appointment availability, and lack of transportation. Two participants described delaying $\mathrm{HCV}$ care because of restrictions on $\mathrm{HCV}$ treatment during pregnancy. Structural barriers tended to occur in multiples, as evidenced in one gentleman's concerns about successful follow-through with treatment: "I got money issues, transportation issues. And quite frankly, I'm a little scared to make a commitment because I don't know whether I can honor the commitment because of my near homelessness and financial capabilities and transportation capabilities. I hate to say I'll be here at some certain time and then I can't find a ride, ya know. I would definitely love to pursue [HCV treatment]" [participant 10, male, 61 years].

Perceived financial barriers posed a common challenge. The perception of HCV treatment as being costprohibitive was based on prior experience with insurance company denials for HCV treatment, awareness of the high cost of $\mathrm{HCV}$ medication, or belief that insurance will not cover expensive medications. Patients perceived the cost of medication to be exorbitant, including one who expected the cost to be "thousands of dollars...It's not like a house payment. It's more like a whole house" [participant 7, female, 70 years].

Clinic level factors constituted barriers to care including difficulty contacting clinic staff, limited appointment availability, and gaps in time between referral and date of initial visit. Trust in the medical system and concerns regarding confidentiality were additional clinic level perceived barriers. Participants also expressed frustration with prior experiences pursuing $\mathrm{HCV}$ care that did not ultimately result in treatment due to prior restrictions on treatment and resulting loss of care connection. Recalling a prior visit with an HCV specialist, a participant recalled discussing treatment and "that's all I remember, ya know, possible treatment. I don't know if it was on my end. It just kind of fizzled out. Things never happened after that." [Participant 6, male, 64 years]

Participants proposed modifications to the care process that would allow them to overcome barriers and pursue treatment, including changes regarding insurance/cost $(n=4)$, social support from friends and family serving as a source of motivation (3), transportation to and from appointments and required studies (2), more flexible scheduling (1), ability to easily contact doctors (1), medication side effects (1), more knowledge of the process (1), and addressing addiction (1). One participant suggested the process would be more accessible to patients if streamlined and "you could do it all at one time instead of three different appointments...It was hard enough for me to go to one" [participant 2, male, 31 years]. Four participants described their ability to overcome financial barriers by obtaining insurance through a new job or by working with clinic staff to access financial assistance programs. All participants were confident in their self-efficacy to pursue HCV treatment if they decided to do so, drawing on experiences taking medications and attending appointments for other 
Table 1 Participant characteristics, healthcare experiences, barriers to care, and self-reported substance use history $(N=11)$

\begin{tabular}{ll}
\hline Characteristic & $N(\%)$ \\
\hline Demographic characteristics
\end{tabular}

Age group

$$
\begin{aligned}
& \text { 20-39years } \\
& 40-59 \text { years } \\
& \geq 60 \text { years }
\end{aligned}
$$$$
\text { Sex }
$$

$$
\text { Male }
$$$$
\text { Female }
$$

Race

White

Black

Indian American

Referral year

2015

2016

2017

2018

\section{Healthcare experiences}

Healthcare access

Has an established primary care provider

Visited emergency room in past year

Has seen any doctor in past year

Health insurance status

$$
\begin{aligned}
& \text { Uninsured } \\
& \text { Insured } \\
& \text { Private insurance } \\
& \text { Medicaid } \\
& \text { Medicare } \\
& \text { Setting of HCV diagnosis } \\
& \text { Routine bloodwork by physician } \\
& \text { Donating blood } \\
& \text { Bloodwork while incarcerated } \\
& \text { Screening at a methadone program } \\
& \text { Knowledge of hepatitis C status } \\
& \text { Knowledge of hepatitis C specialty referral }
\end{aligned}
$$

\section{Barriers to care}

\section{Unreliable transportation}

$$
\text { Yes }
$$

No

Unstable housing ${ }^{\text {a }}$

$$
\text { Yes }
$$

\begin{tabular}{|c|c|}
\hline Characteristic & $N(\%)$ \\
\hline Excellent & $0(0)$ \\
\hline Very good & $3(27)$ \\
\hline Good & $4(36)$ \\
\hline Fair & $2(18)$ \\
\hline Poor & $2(18)$ \\
\hline \multicolumn{2}{|c|}{ Trust in medical system ${ }^{\mathrm{b}}$, possible scores 5 to 25} \\
\hline Median score [interquartile range] & 18 [12-19] \\
\hline Minimum score & 9 \\
\hline Maximum score & 25 \\
\hline \multicolumn{2}{|l|}{ Substance use history } \\
\hline \multicolumn{2}{|l|}{ Drug use } \\
\hline In the past month & $3(27)$ \\
\hline In past year & $5(45)$ \\
\hline \multicolumn{2}{|l|}{ Alcohol Use $^{d}$} \\
\hline In the past month & $2(18)$ \\
\hline In past year & $4(36)$ \\
\hline \multicolumn{2}{|l|}{ Treatment for substance use disorder } \\
\hline Any prior treatment & $6(55)$ \\
\hline Alcohol & $2(18)$ \\
\hline Drug use & $3(36)$ \\
\hline Both & $1(9)$ \\
\hline No prior treatment & $5(45)$ \\
\hline
\end{tabular}

No

Rating of own health
Table 1 Participant characteristics, healthcare experiences, barriers to care, and self-reported substance use history $(N=11)$ (Continued)

LTC linkage to care

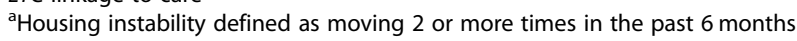
or concerned about housing stability in the upcoming 6 months $[29,30]$ ${ }^{\text {b}}$ Trust in medical system is quantified based on response to five questions and potential scores can range from 5 to 25 , with higher scores indicating more trust [27]

'Drug screen single question, "How many times in the past month have you used an illegal drug or used a prescription medication for non-medical reasons?", Any response $\geq 1$ time is positive for drug use [31]

${ }^{d}$ Alcohol single question screen, How many times in the past month have you had $X$ or more drinks in a day?, ( $X=5$ for men, $X=4$ for women) [32]

medical problems as a source of confidence. One participant, who had attempted an earlier interferon-based regimen, reported concerns regarding side effects even for the newer, shorter course of medication: "It's terrible what [interferon] does to you...This eight weeks crap's got to go. That's just shoving too much medication at one time is what it is" [participant 4, male, 51 years].

\section{Stigma}

Stigma prevented some participants from pursuing care. Perceived stigma could be related to poverty, lack of insurance, or HCV infection and was based on prior experiences with the healthcare system. One participant who perceived stigma to be a barrier noted that "I do feel in general, the population is looked down on if you don't 
Table 2 Hepatitis $C$ knowledge questions and response rates $(n=11)$

\begin{tabular}{ll}
\hline Hepatitis C knowledge questions & $\begin{array}{l}\text { Correct responses } \\
N(\%)\end{array}$ \\
\hline $\begin{array}{l}\text { Most people with hepatitis C do not have } \\
\text { symptoms. }\end{array}$ & $9(82)$
\end{tabular}

True, false

Most people with hepatitis $C$ know they are infected.

\section{True, false}

A person who injected drugs one time should be tested for hepatitis $C$.

True, false

A person born between 1945 and 1965 should be tested for hepatitis C.

True, false

Hepatitis $C$ can cause:

Cirrhosis, liver failure, liver cancer, all of the above

With treatment, what percent of people with hepatitis $C$ can be cured?

\section{$<25 \%, 50 \%, 75 \%$, > 90\%}

Answer choices are in italics following question stem. Correct answer choice is in bold. Questions are adapted from the Centers for Disease Control Hepatitis $\mathrm{C}$ fact sheet, the World Health Organization Hepatitis $\mathrm{C}$ webpage, and Zeremski et al. [34]

have insurance or underpaid or whatever the case may be. I feel like I'm in that category, which I am." [Participant 6, male, 64years]. For one participant who perceived $\mathrm{HCV}$-related stigma, he described his experience seeking medical care as "I go into the doctor's office with that stigma like, here comes that dude with that hep C - everybody glove up" [participant 4, male, 51 years]. One patient who was referred to the infectious diseases HCV clinic remembered an event where "the call that came up on the caller identification at work said infectious disease clinic. At that time, I felt like I had just been labeled... I felt violated" [participant 1, female, 47 years].

Conversely, other participants did not perceive stigma to be a factor in their decision to pursue care. For these participants, experiences with healthcare led them to believe "most people in the medical field are pretty respectful people and try to understand what people are going through." [participant 2, male, 31 years]. As another describes, "I don't expect to be treated any differently, just as a normal patient that has a disease that needs to be cured" [participant 5, female, 29 years].

While substance use was identified as the primary risk factor for $\mathrm{HCV}$ infection, substance use was not perceived to be a barrier to care. One participant noted "[HCV] is a common disease. I mean, a lot of people have it. You can get it from using dirty needles. I think most of the populous believes people that have hep $C$ got it from dirty needles, which is a stigma. But I'm not worried about that." [Participant 10, male, 61 years]. This participant identified substance use to be beneficial to his relationship with the healthcare system because "now I can have a little access to medical services; I believe I wouldn't have access to if I wasn't a substance abuser" [participant 10, male, 61 years]. Concerns regarding reinfection with $\mathrm{HCV}$ among those with ongoing substance use did not arise.

Table 3 Major themes associated with pursuit of care based on qualitative patient interviews, associated Health Belief model constructs, and suggested interventions to improve care

\begin{tabular}{|c|c|c|}
\hline Major themes & $\begin{array}{l}\text { Associated Health Belief } \\
\text { Model constructs }\end{array}$ & Proposed interventions to improve care \\
\hline $\begin{array}{l}\text { Structural barriers: financial, } \\
\text { scheduling, transportation, } \\
\text { health-system level }\end{array}$ & Perceived barriers & $\begin{array}{l}\text { Expand Medicaid; utilize pharmaceutical company drug assistance programs; } \\
\text { educate patients on available resources and supportive care; aim for clinic } \\
\text { responsiveness, ease of scheduling, and confidentiality }\end{array}$ \\
\hline Stigma & $\begin{array}{l}\text { Perceived susceptibility } \\
\text { Perceived barriers }\end{array}$ & $\begin{array}{l}\text { Provide education on harm reduction strategies; co-locate treatment for sub } \\
\text { stance use disorder and HCV; educate clinic staff on creating a welcoming } \\
\text { atmosphere }\end{array}$ \\
\hline Ambivalence & $\begin{array}{l}\text { Perceived susceptibility } \\
\text { Perceived severity }\end{array}$ & $\begin{array}{l}\text { Acknowledge and address the uncertainty related to having HCV; Focus patient } \\
\text { education campaigns on ambivalence and the potential for treatment to relieve } \\
\text { patients of the burden of uncertainty }\end{array}$ \\
\hline $\begin{array}{l}\text { Prior experiences of HCV } \\
\text { disease and treatment }\end{array}$ & $\begin{array}{l}\text { Perceived susceptibility } \\
\text { Perceived severity } \\
\text { Perceived benefits } \\
\text { Perceived barriers }\end{array}$ & $\begin{array}{l}\text { Explore patients' or others' prior experiences with HCV treatment; address } \\
\text { favorable changes in treatment since earlier therapies }\end{array}$ \\
\hline Patient-provider relationship & $\begin{array}{l}\text { Perceived susceptibility } \\
\text { Perceived severity } \\
\text { Perceived barriers } \\
\text { Perceived benefits } \\
\text { Self-efficacy }\end{array}$ & $\begin{array}{l}\text { Encourage expansion of HCV treatment to where patients are already receiving } \\
\text { care and have established relationships }\end{array}$ \\
\hline
\end{tabular}




\section{Ambivalence}

A sense of discordance between perceived severity and perceived susceptibility emerged across interviews. Most participants perceived $\mathrm{HCV}$ to be a severe infection associated with complications such as liver failure, cirrhosis, and cancer as well as symptoms including fatigue, changes in mood, sleep disturbances, and jaundice. Yet, participants did not perceive that they experienced symptoms attributable to $\mathrm{HCV}$, nor did they perceive themselves to be susceptible to negative outcomes.

This discordance was reflected in a participant's answer when asked if $\mathrm{HCV}$ is a serious medical condition: "In general yes, I think so. In my case, I don't know" [participant 6, male, 64 years]". Another participant explained: "for me, it's apparently in a dormant stage. It just keeps being dormant. It hasn't affected me. I don't have yellow eyes or anything like that. It hasn't noticeably affected my health...But at any time, it could jump up and affect me gravely. But so far it hasn't." [Participant 10, male, 61 years]

Another participant expressed his knowledge of HCV: "my understanding, basically, is that it can attack your liver. It can cause cirrhosis of the liver" [participant 1 , female, 47 years], while also stating "all diseases are serious. I think [HCV] is something you can live with" [participant 1, female, 47 years]. The perception of HCV as a disease that can be lived with was shared by others, including one who explained "I'm looking at my hepatitis C like prostate cancer. Men die with prostate cancer. They don't die of it. I'm probably going to die with my hepatitis $C$ not of it" [participant 4 , male, 51 years]. Perceiving HCV to be a disease that can be safely lived with contributed to decisions not to pursue care.

\section{Prior experiences of HCV disease and treatment}

Experience with the course of $\mathrm{HCV}$ disease and treatment could occur through participants' own pursuit of treatment or others'. At time of HCV diagnosis, participants found reassurance in the stories of family and friends who had been cured with DAA-based regimens, including a participant who noted: "[My husband] went through the VA Hospital and had to take treatments. And he's been cured." [Participant 1, female, 47 years], and another who explained: "I've never seen anybody actually sick from it. People have told me they've had it. But I never met anybody who had it in an active stage [participant 10, male, 61 years]. Others who knew of family and friends' experience with severe illness and complications related to $\mathrm{HCV}$ reported fear and concern on diagnosis. "I know someone who has it who was hospitalized over it. I kind of knew about it already and what to expect. Once I found out I had it, I just kind of freaked out for a minute and blocked everything out trying to deal with my own thoughts." [Participant 3, female, 24 years]

Prior experiences with interferon-based treatment led to the perception of treatment to be potentially harmful. One patient who had trialed interferon stated "[The interferon] made me feel like I was going to die, man... And that is the reason why I will not be treated - because the medication is so dangerous." [Participant 4, male, 51 years]. Another participant, who had not sought treatment himself, described his friend's experience with interferon: "I had a buddy of mine that was given the interferon, and it made him so weak, I had to help him from his couch to the bathroom. He used to give himself three injections a week in the stomach. I said man, I just couldn't go through that" [participant 8 , male, 55 years].

\section{Patient-provider relationship}

The relationship between patients and healthcare providers influenced nearly all HBM constructs. Both longstanding and short-term relationships could be impactful, and the presence of trust within these relationships affected the quality of the interactions and influence on patient perceptions. Patient-provider relationships were most important when either the interaction occurred at a key step in the disease process, such as at time of diagnosis, or when based on a long-standing trusted relationship.

Receiving a diagnosis of HCV led to feelings of confusion ("where did it come from?" [participant 1, female, 47 years]), surprise ("I wasn't sick. At least I didn't think I was" [participant 6, male, 64 years]), and fear ("I thought I was going to die" [participant 7, female, 70 years]). Participants who interacted with healthcare providers at the time of their diagnosis cited counseling as a way to mitigate negative initial impressions. One participant reflected that "the lady that did [the test] told me that I could get treatment. It eased my mind" [participant 3, female, 24 years]. When this interaction was not present, such as for patients informed of their results through letters, feelings of bewilderment and confusion persisted.

Participants noted trusted relationships with longstanding primary care providers to be sources of motivation for pursuing treatment. One participant described how their doctor's behavior built a trusting relationship: "I felt like my doctor was very open, honest, and straightforward. He told me about things I could do to lessen my chances of [HCV] getting worse...I say that's the most important thing. Just be straightforward and be honest about what your prognosis is, what you need to quit doing to improve your chances, keeping from spreading it to other people. I was given all those things" [participant 7, female, 70 years]. Trusted providers were seen as potential facilitators of the treatment process, if 
the decision were made to seek care: "All I got to do [to get treated] is ask my family physician. My internal medicine doctor, she's very adamant about trying to get me cured" [participant 4, male, 51 years], and "I feel like now that my doctors know everything - whatever I have going on, my doctor and I are very close. I can tell her anything. I feel like she would help me get into the clinic if I needed to rather than just me trying to do it on my own and not getting any answers." [Participant 3, female, 24 years]

Conversely, a lack of trust with health care providers also informed patients' decisions not to seek treatment. A patient with previous experience with earlier interferon-based treatment was discouraged by a lack of responsiveness by prior HCV specialists to his concerns, and this resulted in a lack of trust that impacted his perceived benefits of treatment. "I had taken the pill one time. And it made me sick. It made me feel like I was going to die, man. And I tried to explain it to the doctor...And the doctors just act like it ain't no big deal.... I can't trust [doctors] at all...It's a serious disease. They need to treat it as one... I'd rather die from the disease than die from some cure." [Participant 4, male, 51 years]

\section{Discussion}

In this population of patients who have been diagnosed with HCV and referred to specialty care, but who have not successfully linked to care, excellent HCV knowledge was not sufficient for participants to pursue care. We identified themes that influenced pursuit of $\mathrm{HCV}$ care. The behavior of not seeking care resulted from complicated and varied factors across individual and structural levels. Dominant themes influencing pursuit of care included structural barriers to care, stigma, prior experiences with HCV through self or others, ambivalence, and patient-provider relationships. Improving LTC, and overcoming the plateau in LTC rates, requires systematic changes in care.

Structural barriers to care related to social determinants of health are prevalent. In the HBM, perceived barriers to care are one of the strongest predictors of health behavior [36]. Housing instability, unreliable transportation, drug and alcohol use, and lack of insurance have all been previously identified to be barriers to care [12-19, 37] and were common in our population. Lack of insurance and financial status were commonly perceived to be barriers, despite our clinic's ability to access treatment for all patients, regardless of insurance status. Multiple participants hoped to overcome financial barriers by obtaining insurance to cover $\mathrm{HCV}$ treatment. Awareness of programs to overcome perceived financial barriers is needed among our population. Recent expansion of Medicaid, a government sponsored health insurance, in our state provides an opportunity for additional insurance coverage, which may help overcome this prominent barrier. Medicaid expansion may also provide additional resources to address transportation, another commonly cited barrier. Pregnancy arose as a barrier for two women; current $\mathrm{HCV}$ treatment guidelines do not recommend treatment during pregnancy [38]. Therefore clinics need to maintain a relationship with pregnant patients in order to provide access to treatment when it is appropriate in the future. Patients also raised concerns about clinic level factors including scheduling availability, responsiveness to calls, and concerns regarding confidentiality, including the possibility of inadvertent disclosure that a patient receives care at an infectious disease clinic. Limited timeframes for available appointments can impact patients' ability to attend appointments. Simplifications to the HCV care model have been proposed, including rapid testing, test-andtreat models, minimal on-treatment monitoring, and limited patient visits, which may serve to reduce barriers, make treatment more accessible, and facilitate treatment expansion [39].

People who use drugs are a key population to target for HCV treatment [38], and the majority of our participants reported a history of substance use. Yet, in contrast to prior studies, substance use was not identified to be a barrier to care [40]. Participants reported stigma to be a factor influencing pursuit of HCV care; however, stigma was attributed to poverty, lack of insurance, or $\mathrm{HCV}$ infection itself, rather than to substance use. Our findings may differ from prior studies for multiple reasons. At a clinic level, our HCV clinic is co-located with a Ryan White HIV/AIDS program clinic, and clinic staff are accustomed to caring for patients with a stigmatized illness. At a policy level, our state does not have sobriety restrictions related to treatment access, though restrictions remain elsewhere in the country [41]. Among people who use drugs, HCV treatment can be a motivating factor to reduce substance use and/or to participate in harm reduction activities [42, 43]. For one participant, substance use was his main source of connection to healthcare systems. This highlights the importance of ensuring HCV treatment programs, and substance use treatment programs offer bidirectional referrals to provide comprehensive patient care, promote access to care, and potentially simplify care if services were to be colocated. A risk of $\mathrm{HCV}$ reinfection from ongoing substance use did not emerge as a perceived barrier to care.

Ambivalence arose as discordance between perceived severity of $\mathrm{HCV}$ for others relative to perceived personal susceptibility to HCV complications. People living with HCV experience a sense of "sustained uncertainty" [44]. This uncertainty can relate to the potential development of complications at an unknown future date, misinformation, or lack of knowledge regarding $\mathrm{HCV}[44,45]$. 
While DAAs have drastically improved the effectiveness and ease of treatment, this new era of treatment may not be influencing established patient narratives of HCV illness, limiting the uptake of new treatments [46]. To reach these patients, it may be helpful to highlight improvements in patient-related outcomes with $\mathrm{HCV}$ cure [3]. The most significant impact of HCV cure may be an improved sense of psychological wellbeing related to relief about no longer living with the burden of an uncertain future or the fear of transmitting the infection to others [43]. Addressing the uncertainty of living with HCV and the potential to alleviate this uncertainty through treatment may be a strategy to address ambivalence.

Prior experiences with HCV care through either personal experiences or those of family and friends are common and influenced all HBM constructs. Some patients have experienced discontinuous HCV care [47], in which patients diagnosed prior to DAA therapy have been lost to HCV care. Experience with interferon-based treatment regimens can motivate some patients to seek the more patient-friendly DAA treatment [48], though in our study, the severe side effects associated with interferon persist in patients' memories and discourage them from reconnecting to care. People living with $\mathrm{HCV}$ have varied reasons for not pursuing care, and providers should explore patient perceptions, including knowledge of others' experiences with HCV treatment, and an individual's own prior experiences.

Established patient-provider relationships influence perceived barriers and self-efficacy. The quality of these patient-provider relationships determines if they serve as barriers or facilitators to care. Positive patient-provider relationships are beneficial in $\mathrm{HCV}$ treatment $[48,49]$. Multiple patients cited their trusted provider as a key source of motivation for pursuing treatment and someone they could turn to for assistance. As most participants had seen a doctor in the prior year, HCV treatment could build on established relationships by expanding to sites where patients are already receiving care such as primary care practices, health departments, or substance use disorder treatment programs [50]. Expansion into other sites of care may also serve to decrease logistical barriers and decrease stigma. Yet, primary care providers remain hesitant to treat $\mathrm{HCV}$, and HCV providers hesitate to treat those with substance use, resulting in limited uptake of these models of care [51-53].

Notable limitations of our study include inability to contact a majority of those who did not link to care in our clinic. Low participation may have been due to recruiting over the telephone, which is a communication method through which it can be harder for a researcher who is unknown to the participant to build rapport. Patients who could not be contacted may have different experiences living with $\mathrm{HCV}$, including unstable phone numbers, which likely impacts their experience seeking care. Additionally, many of those contacted declined participation, and this may be related to prior experiences with the healthcare system, competing priorities, or other factors. Eligible participants may have been referred to the clinic over a year prior to the time of recruitment, and over that time patients may have changed phone numbers or forgotten about the referral, limiting recruitment. Our data is limited to the UVA health system, and eligible participants may have sought outside HCV care. Although our sample size was small, we were able to achieve thematic saturation in our analysis of the interviews, which suggests that the sample was adequate to elicit a consistent set of themes. The analysis revealed barriers to care linkage experienced by interview respondents, related to underlying social determinants of health. Generalizability of our findings is limited by our clinic structure. Use of a nursenavigator model likely contributed to participants' excellent $\mathrm{HCV}$ knowledge, as the nurse provides education over the phone while discussing the logistics of referral. However, not all clinics have a dedicated full-time nurse coordinator able to provide this level of education and coordination. While our study was initially designed using the HBM to structure interviews, we found limitations of this model. The model focuses on the individual, and the HBM constructs do not directly account for social, environmental, or emotional factors that impact health behaviors. During qualitative interviews, structural barriers arose as a key factor in perceptions of HCV care. For this reason, we performed our analysis using qualitative content analysis to identify higher level themes that emerged across constructs.

\section{Conclusions}

Basic knowledge about HCV was important, but not sufficient, for patients to pursue care as barriers prevent patients from acting on this knowledge. Barriers occur at the individual and structural level, and nearly half of eligible patients could not be contacted demonstrating that current care methods, especially telephone coordination, are not sufficient to reach a large proportion of people with $\mathrm{HCV}$ who could benefit from treatment. Overcoming the recent plateau in LTC rates will require changes in models of care. On an individual level, public health campaigns should focus on the ease of treatment, address the uncertainty that arises regarding how hepatitis $\mathrm{C}$ will affect one's own health, and emphasize potential improvements in patient-related outcomes with treatment. Expanding access to health insurance may overcome perceived financial barriers. Providing HCV care in settings with an established patient-provider relationship, or in conjunction with substance use treatment programs, may increase treatment uptake. 


\section{Supplementary information}

Supplementary information accompanies this paper at https://doi.org/10. 1186/s12954-020-00409-9.

Additional file 1: Table S1. Study codebook including codes, definitions, and example quotes with frequency of occurrence.

\section{Abbreviations}

HCV: Hepatitis C virus; DAAs: Direct-acting antivirals; LTC: Linkage to care; UVA: University of Virginia; HBM: Health Belief Model

\section{Acknowledgements}

We thank the clinic patients who shared their stories, Samuel Eger for his assistance in performing interviews, and our current and former hepatitis C clinic coordinators, Marsha Rodeffer, Debbie Childs, Terry Kemp Knick, and Jeanell Webb-Jones.

\section{Authors' contributions}

JES, KAM, RD, TK, and TF developed the study and collaborated on the study materials. AT performed interviews. AT, JES, and TF coded and analyzed the interviews. JS wrote the initial draft of the manuscript. All authors read and approved the final manuscript.

\section{Funding}

This work was supported by the National Institute of Allergy and Infectious Diseases [grant number T32 Al007046-43 to JES]. This work was also supported by the National Institute of Allergy and Infectious Diseases of the National Institutes of Health [grant number K08Al136644 to KAM].

\section{Availability of data and materials}

The datasets generated and/or analyzed during the current study are not publicly available due to the sensitive and personal nature of qualitative interviews but are available from the corresponding author on reasonable request.

\section{Ethics approval and consent to participate}

This study was approved by the University of Virginia Institutional Review Board for Health Sciences Research. All participants provided verbal, informed consent prior to participation in the study.

\section{Consent for publication}

Not applicable

\section{Competing interests}

KAM reports stock ownership in Gilead Sciences, Inc. RD provides consulting services for Warm Health Technologies, an mHealth company. RD and KAM are recipients of an investigator-initiated grant from Gilead Sciences, Inc. All other authors declare no competing interests.

\section{Author details}

'Division of Infectious Diseases and International Health, Department of Medicine, University of Virginia, Charlottesville, VA, USA. ' University of Virginia School of Medicine, Charlottesville, VA, USA. ${ }^{3}$ Division of General, Geriatric, Palliative, and Hospital Medicine, Department of Medicine, University of Virginia, Charlottesville, VA, USA.

Received: 17 April 2020 Accepted: 26 August 2020

Published online: 18 September 2020

\section{References}

1. National Academies of Sciences Engineering and Medicine. A national strategy for the elimination of hepatitis B and C: phase two report [Internet]. Washington DC; 2017 [cited 2019 Sep 27]. Available from: http://www. nationalacademies.org/hmd/reports/2017/national-strategy-for-theelimination-of-hepatitis-b-and-c.aspx.

2. World Health Organization. Hepatitis C [Internet]. [cited 2019 Nov 14]. Available from: https:/www who.int/news-room/fact-sheets/detail/ hepatitis-c.
3. Younossi Z, Papatheodoridis G, Cacoub P, Negro F, Wedemeyer H, Henry L, et al. The comprehensive outcomes of hepatitis $C$ virus infection: a multifaceted chronic disease. J Viral Hepat. 2018 Nov 1;25:6-14.

4. Zelenev A, Li J, Mazhnaya A, Basu S, Altice FL. Hepatitis C virus treatment as prevention in an extended network of people who inject drugs in the USA: a modelling study. Lancet Infect Dis. 2018 Feb 1;18(2):215-24.

5. Jordan AE, Perlman DC, Reed J, Smith DJ, Hagan H. Patterns and gaps identified in a systematic review of the hepatitis $C$ virus care continuum in studies among people who use drugs. Front Public Heal [Internet]. 2017 Dec 18 [cited 2020 Apr 11];5:348. Available from: http://www.ncbi.nlm.nih. gov/pubmed/29326922.

6. Reau N, Marx S, Manthena S, Strezewski J, Chirikov V. National examination of HCV linkage to care in the United States (2013-2016) based on large realworld dataset. Hepatology. 2018;68:892A-3A.

7. Cachay ER, Hill L, Torriani F, Ballard C, Grelotti D, Aquino A, et al. Predictors of missed hepatitis $C$ intake appointments and failure to establish hepatitis C care among patients living with HIV. Open Forum Infect Dis [Internet]. 2018 Jul 1 [cited 2019 Nov 22];5(7). Available from: https://academic.oup. com/ofid/article/doi/10.1093/ofid/ofy173/5062980.

8. Zibbell JE, lqbal K, Patel RC, Suryaprasad A, Sanders KJ, Moore-Moravian L, et al. Increases in hepatitis $C$ virus infection related to injection drug use among persons aged $\leq 30$ years - Kentucky, Tennessee, Virginia, and West Virginia, 2006-2012. MMWR Morb Mortal Wkly Rep [Internet]. 2015;64(17): 453-8. Available from: https://www.cdc.gov/mmwr/preview/mmwrhtml/ mm6417a2.htm

9. Rosenberg ES, Rosenthal EM, Hall EW, Barker L, Hofmeister MG, Sullivan PS, et al. Prevalence of hepatitis C virus infection in US states and the District of Columbia, 2013 to 2016. JAMA Netw open [Internet]. 2018 [cited 2019 Sep 23];1(8):e186371. Available from: http://www.ncbi.nlm. nih.gov/pubmed/30646319.

10. Zampino R, Coppola N, Di Caprio G, Sagnelli C, Sagnelli E. Hepatitis C virus infection and prisoners: epidemiology, outcome and treatment. Vol. 7 , World Journal of Hepatology. Baishideng Publishing Group Co; 2015. p. 2323-2330.

11. Degenhardt L, Peacock A, Colledge S, Leung J, Grebely J, Vickerman P, et al. Global prevalence of injecting drug use and sociodemographic characteristics and prevalence of HIV, HBV, and HCV in people who inject drugs: a multistage systematic review. Lancet Glob Health. 2017; 5(12):e1192-207.

12. Cloud DH, Ibragimov U, Prood N, Young AM, Cooper HLF. Rural risk environments for hepatitis $C$ among young adults in Appalachian Kentucky. Int J Drug Policy. 2019 Oct 1;72:47-54.

13. Grebely J, Hajarizadeh B, Lazarus JV, Bruneau J, Treloar C. Elimination of hepatitis $C$ virus infection among people who use drugs: ensuring equitable access to prevention, treatment, and care for all. Int J Drug Policy. 2019 Oct $1 ; 72: 1-10$

14. Wright C, Cogger S, Hsieh K, Goutzamanis S, Hellard M, Higgs P. "I'm obviously not dying so it's not something I need to sort out today": considering hepatitis C treatment in the era of direct acting antivirals. Infect Dis Heal. 2019 May 1;24(2):58-66.

15. Harris M, Bonnington O, Harrison G, Hickman M, Irving W, Roberts K, et al. Understanding hepatitis C intervention success-qualitative findings from the HepCATT study. J Viral Hepat. 2018 Jul 1;25(7):762-70.

16. Henderson C, Madden A, Kelsall J. 'Beyond the willing \& the waiting' - the role of peer-based approaches in hepatitis C diagnosis \& treatment. Vol. 50, International Journal of Drug Policy. Elsevier B.V.; 2017. p. 111-5.

17. Sherbuk JE, McManus KA, Kemp Knick T, Canan CE, Flickinger TE, Dillingham $R$. Disparities in hepatitis C linkage to care in the direct acting antiviral era: findings from a referral clinic with an embedded nurse navigator model. Front Public Health. 2019;7:362.

18. Poll R, Allmark P, Tod AM. Reasons for missed appointments with a hepatitis C outreach clinic: a qualitative study. Int J Drug Policy. 2017 Jan 1;39:130-7.

19. Morrill JA, Shrestha M, Grant RW. Barriers to the treatment of hepatitis C: patient, provider, and system factors. J Gen Intern Med. 2005 Aug;20(8):754-8.

20. Becker M. Health Belief Model and personal health behavior. Thorofare, NJ: Slack Inc: 1974.

21. Janz N, Champion V, Strecher V. The health belief model. In: Glanz K, Rimer BK LF, editor. Health behavior and health education: theory, research and practice. 4th ed. Plano, TX: Jossey-Bass; 2008. p. 45.

22. Rosenstock IM. Why people use health services. Vol. 83, Milbank Quarterly. Blackwell Publishing Inc.; 2005. 
23. Glanz K, Bishop DB. The role of behavioral science theory in development and implementation of public health interventions. Annu Rev Public Health. 2010 Mar;31(1):399-418.

24. Institute of Medicine. America's health care safety net [Internet]. The National Academies Press. Washington, D.C.: National Academies Press; 2000 [cited 2020 Aug 1]. Available from: https://www.nap.edu/catalog/9612/ americas-health-care-safety-net-intact-but-endangered.

25. Drabble L, Trocki KF, Salcedo B, Walker PC, Korcha RA. Conducting qualitative interviews by telephone: lessons learned from a study of alcohol use among sexual minority and heterosexual women. Qual Soc Work [Internet]. 2016 Jan 1 [cited 2020 Aug 1];15(1):118-33. Available from: https://pubmed.ncbi.nlm.nih.gov/26811696/.

26. Novick $\mathrm{G}$. Is there a bias against telephone interviews in qualitative research? [Internet]. Vol. 31, Research in Nursing and Health. NIH Public Access; 2008 [cited 2020 Aug 1]. p. 391-8. Available from: /pmc/articles/ PMC3238794/?report = abstract.

27. Dugan E, Trachtenberg F, Hall MA. Development of abbreviated measures to assess patient trust in a physician, a health insurer, and the medical profession. BMC Health Serv Res. 2005;3:5.

28. Liao Y, Bang D, Cosgrove S, Dulin R, Harris Z, Stewart A, et al. Surveillance of health status in minority communities - racial and ethnic approaches to community health across the U.S. (REACH U.S.) risk factor survey, United States, 2009. Morb Mortal Wkly Rep [Internet]. 2011 May 20 [cited 2019 Nov 14];60(SS-6):1-41. Available from: https://www.cdc.gov/mmwr/preview/ mmwrhtml/ss6006a1.htm?s_cid\%3Dss6006a1_x.

29. Rollins C, Glass NE, Perrin NA, Billhardt KA, Clough A, Barnes J, et al. Housing instability is as strong a predictor of poor health outcomes as level of danger in an abusive relationship: findings from the SHARE study. J Interpers Violence. 2012;27(4):623-43.

30. Cox R, Henwood B, Wenzel S, Rice E. Roadmap to a unified measure of housing insecurity [Internet]. CESR-Schaeffer Working Paper No. 2016-013. [cited 2019 Nov 15]. Available from: https://ssrn.com/abstract=2817626.

31. Smith PC, Schmidt SM, Allensworth-Davies D, Saitz R. A single-question screening test for drug use in primary care. Arch Intern Med. 2010 Jul 12; 170(13):1155-60.

32. Smith PC, Schmidt SM, Allensworth-Davies D, Saitz R. Primary care validation of a single-question alcohol screening test. J Gen Intern Med. 2009 Jul;24(7):783-8.

33. Centers for Disease Control and Prevention. Hepatitis $C$ general information [Internet]. [cited 2019 Nov 14]. Available from: https://www.cdc.gov/ hepatitis/HCV/PDFs/HepCGeneralFactSheet.pdf.

34. Zeremski M, Dimova RB, Zavala R, Kritz S, Lin M, Smith BD, et al. Hepatitis C virus-related knowledge and willingness to receive treatment among patients on methadone maintenance. J Addict Med. 2014;8(4):249-57.

35. Hsieh HF, Shannon SE. Three approaches to qualitative content analysis. Qual Health Res. 2005 Nov;15(9):1277-88.

36. Carpenter CJ. A meta-analysis of the effectiveness of Health Belief Model variables in predicting behavior. Health Commun [Internet]. 2010 Nov 30 [cited 2020 Apr 14];25(8):661-9. Available from: http://www.tandfonline. com/doi/abs/10.1080/10410236.2010.521906.

37. Sherbuk JE, McManus KA, Rogawski McQuade ET, Knick T, Henry Z, Dillingham R. Hepatitis $C$ within a single health system: progression along the cascade to cure is higher for those with substance misuse when linked to a clinic with embedded support services. Open forum Infect Dis [Internet]. 2018 Sep [cited 2019 Sep 27];5(9):ofy202. Available from: http:// www.ncbi.nlm.nih.gov/pubmed/30255113.

38. AASLD-IDSA. Recommendations for testing, managing, and treating hepatitis C [Internet]. [cited 2019 Sep 30]. Available from: http://www. hcvguidelines.org.

39. Kapadia SN, Marks KM. Hepatitis C management simplification from test to cure: a framework for primary care providers. Clin Ther. 2018 Aug 1; 40(8):1234-45

40. Skeer MR, Ladin K, Wilkins LE, Landy DM, Stopka TJ. 'Hep C's like the common cold': understanding barriers along the HCV care continuum among young people who inject drugs. Drug Alcohol Depend. 2018 Sep 1;190:246-54

41. National Viral Hepatitis Roundtable and Center for Health Law and Policy Innovations at Harvard Law School. Hepatitis C: state of Medicaid access [Internet]. 2019 [cited 2019 Sep 27]. Available from: https://stateofhepc.org/.

42. E. Williams B, Nelons D, Seaman A, Witkowska M, Ronan W, Wheelock H, et al. Life projects: the transformative potential of direct-acting antiviral treatment for hepatitis C among people who inject drugs. Int J Drug Policy [Internet]. 2019 Oct [cited 2019 Nov 15];72:138-45. Available from: https:// linkinghub.elsevier.com/retrieve/pii/S095539591930074X.

43. Richmond JA, Ellard J, Wallace J, Thorpe R, Higgs P, Hellard M, et al. Achieving a hepatitis $C$ cure: a qualitative exploration of the experiences and meanings of achieving a hepatitis $C$ cure using the direct acting antivirals in Australia. Hepatol Med Policy. 2018 Dec;3:1.

44. Hill R, Pfeil M, Moore J, Richardson B. Living with hepatitis C: a phenomenological study. J Clin Nurs [Internet]. 2015 Feb [cited 2019 Nov 14];24(3-4):428-38. Available from: http://www.ncbi.nlm.nih.gov/ pubmed/24811299.

45. Goutzamanis S, Doyle JS, Thompson A, Dietze P, Hellard M, Higgs P. Experiences of liver health related uncertainty and self-reported stress among people who inject drugs living with hepatitis $C$ virus: a qualitative study. BMC Infect Dis. 2018;2:18(1).

46. Whiteley D, Whittaker A, Elliott L, Cunningham-Burley S. Hepatitis C in a new therapeutic era: recontextualising the lived experience. J Clin Nurs. 2018 Jul 1;27(13-14):2729-39.

47. Lin M, Kramer J, White D, Cao Y, Tavakoli-Tabasi S, Madu S, et al. Barriers to hepatitis $C$ treatment in the era of direct-acting anti-viral agents. Aliment Pharmacol Ther [Internet]. 2017 Nov [cited 2019 Nov 15];46(10):992-1000. Available from: http://doi.wiley.com/10.1111/apt.14328.

48. Skolnik AA, Noska A, Yakovchenko V, Tsai J, Jones N, Gifford AL, et al. Experiences with interferon-free hepatitis $C$ therapies: addressing barriers to adherence and optimizing treatment outcomes. BMC Health Serv Res. 2019;1:19(1).

49. Rogal SS, Arnold RM, Chapko M, Hanusa BV, Youk A, Switzer GE, et al. The patient-provider relationship is associated with hepatitis $C$ treatment eligibility: a prospective mixed-methods cohort study. PLoS One. 2016;1:11(2)

50. Sherbuk JE, Knick TK, Canan C, Ross P, Helbert B, Cantrell ES, Cantrell CJ, Stallings R, Barron N, Jordan D, McManus KA, Dillingham R. Development of an Interdisciplinary Telehealth Model of Provider Training and Comprehensive Care for Hepatitis C and Opioid Use Disorder in a HighBurden Region. J Infect Dis. 2020;222(Supplement_5):S354-64.

51. Asher AK, Portillo CJ, Cooper BA, Dawson-Rose C, Vlahov D, Page KA. Clinicians' views of hepatitis C virus treatment candidacy with direct-acting antiviral regimens for people who inject drugs. Subst Use Misuse. 2016 Jul 28;51(9):1218-23.

52. Thomson M, Konerman MA, Choxi H, Lok ASF. Primary care physician perspectives on hepatitis $C$ management in the era of direct-acting antiviral therapy. Dig Dis Sci [Internet]. 2016 [cited 2019 Sep 23];61(12):3460-8. Available from: http://www.ncbi.nlm.nih.gov/pubmed/26957497.

53. Naghdi R, Seto K, Klassen C, Emokpare D, Conway B, Kelley M, et al. A hepatitis $C$ educational needs assessment of Canadian healthcare providers. Can J Gastroenterol Hepatol [Internet]. 2017 [cited 2019 Sep 27];2017: 5324290. Available from: http://www.ncbi.nlm.nih.gov/pubmed/28396854.

\section{Publisher's Note}

Springer Nature remains neutral with regard to jurisdictional claims in published maps and institutional affiliations.

Ready to submit your research? Choose BMC and benefit from:

- fast, convenient online submission

- thorough peer review by experienced researchers in your field

- rapid publication on acceptance

- support for research data, including large and complex data types

- gold Open Access which fosters wider collaboration and increased citations

- maximum visibility for your research: over $100 \mathrm{M}$ website views per year

At BMC, research is always in progress.

Learn more biomedcentral.com/submissions 